\title{
Eve E. Slater
}

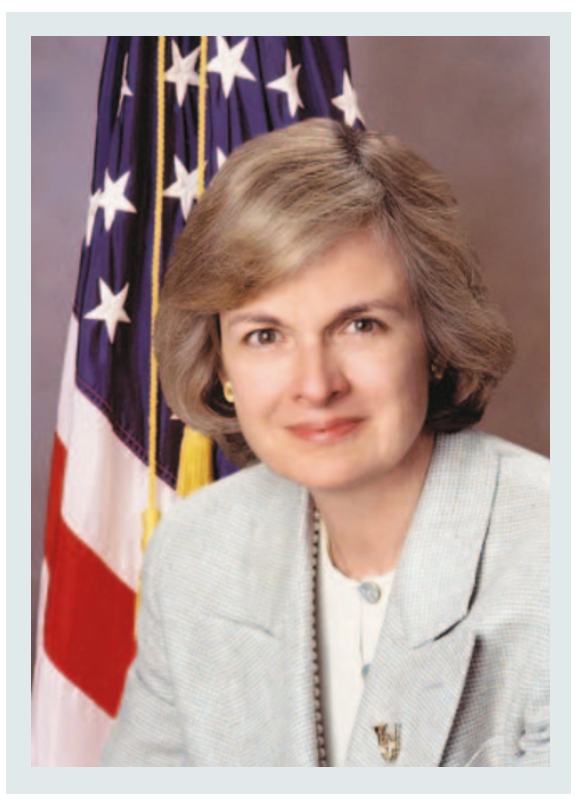

\section{I would still love the FDA job.}

Eve E. Slater has set several precedents for female scientists in her career, having been the first female Chief Resident in Medicine at Massachusetts General Hospital (MGH), the first woman to serve as both Vice President and Senior Vice President at Merck Research Laboratories and the first woman to be appointed as Assistant Secretary for Health in the US Department of Health and Human Services. Understandably, she soon became a much-needed role model: "On my first day at Mass. General, so many of the women medics lined up outside my office, each wanting to discuss individual problems." Slater believes this highlights the desperate need for female role models in science and medicine, something she says she has observed throughout her career: "Women have tended to gravitate towards me for advice, but men have too, although a little less readily. I think it's really important to establish role models whether they be men or women, married or single people. If you've experienced challenges in your career and you have the chance to payback in any way, then you should."

As role models go, she has the benefit of experience from more camps than many, having worked in academia, industry and the government. Leaving Merck and joining the US Government was, she says, perhaps an unconventional move. "The US government has two types of employee: those in civil service who are dedicated to that career path and a top layer of individuals appointed politically. The latter are sometimes distinguished academics, but more often they are people who have been involved in politics at some point. I was unusual, as I had not been involved in politics prior to joining government." Although there were difficulties with moving in that direction - namely having to divest of all stock shares and resign all appointments related to both industry and academics - Slater believes that it's perfectly possible to move from the private sector to the public sector and bring tremendous value. Coming back the other way from government to industry hasn't been fraught with any obvious difficulties, although there is one handicap she hadn't envisaged: "To reenter academia one needs grant support."

Past industry employment did prevent her from being appointed as FDA Commissioner, for which she was considered on several occasions. "I would still love the FDA job", she says, "because I think I could make a

difference. But the government was not, and to my knowledge is still not, interested in taking on someone who has worked for industry. I adamantly disagree with that perspective. I think that one could perform the role without bias because it is a job that is subject to complete transparency. But I'm very comfortable with Andrew von Eschenbach as Acting Commissioner, I think he will do a very good job for the FDA. My understanding is that in the UK the head of the regulatory authority serves a fixed term, and I would certainly opt for a similar term system in the US. I think that the FDA has suffered from lack of consistent leadership so that both Congress and the public can develop trust in someone who can articulate the work and the needs of the agency. A quarter of every dollar spent in the US is on products regulated by the FDA, so I think it's important that people understand what the agency does."

Slater has similar opinions on the lack of transparency in the pharmaceutical industry: "There has been tremendous

\section{I'm ready to solve one more problem before I'm through.}

failure of late on the part of the industry to communicate what it does. Some of the negative public perception is unfair, but I think industry must reinvent itself in a less superficial way. Often when something bad happens within a company its response is to spend more money on advertising, but that's absolutely counter-productive. The industry needs to focus more on drugs that make substantial improvements in health rather than on the marketplace. They should simply boil down their projects to those with a true impact and then be transparent about them."

Slater had left Merck long before Vioxx was recalled. Had she been there, she feels that more resources needed to be devoted to product safety surveillance. "If I were the head of a company, I would reduce the amount of money spent on direct-to-consumer advertising, I would pour resources into product safety surveillance. I would be transparent about how I do this and I would provide the wherewithal to re-educate doctors and patients on how to report possible drug side-effects. I think that if a company did that, meant it, and followed through on it, it would go a huge way to being more responsible and improving the industry's image."

Currently balancing her different roles as teacher and practitioner of medicine as Associate Clinical Professor of Medicine, consulting for and serving on the Board of Directors for several biotech companies, it's a wonder Slater has time to consider her next move. "I've reconstructed the scope of my clinical interests by choosing to work for companies that are complementary to each other and I hope that by doing so I can have an instrumental role in bringing at least one new major therapeutic to market before the end of my career." But she is perhaps ready for one more big job. "Up until maybe a year ago I would have said I've been marvellously lucky with my career, but I'm ready to solve one more problem before I'm through. With that I would be content." 